\title{
I Have Never Felt so Novice: Using Narrative Reflection to Explore the Transition from Expert RN to Novice NP Student
}

\author{
NPOJ 2021, Vol 1, Issue 1 pp.1-8 \\ Erin Ziegler, PhD, NP-PHC ${ }^{1}$ \\ eziegler@ryerson.ca
}

Sarah Kalvoda, RN, BScN, NP-PHC Program ${ }^{1}$

skalvoda@ryerson.ca

Elyse Ancrum-Lee, RN, BScN, NP-PHC Program student ${ }^{1}$

eancrum@ryerson.ca

Erin Charnish, MSc, NP-PHC ${ }^{1}$

erin.charnish@ryerson.ca

1.Daphne Cockwell School of Nursing, Ryerson University, Toronto, Ontario, Canada

\begin{abstract}
Aim: To explore the experiences of nurse practitioner students moving from expert registered nurses to novice nurse practitioner program students.

Background: Moving from registered nurse to nurse practitioner can be a time filled with mixed emotions, lack of confidence, adaptation, and competency development. Learning about and navigating the advanced practice nursing role can be challenging. Students in the nurse practitioner program are encouraged to engage in regular reflective writing to foster role development and learning. This paper aims to reflectively explore the experiences of transition from registered nurse to nurse practitioner student.

Methods: Inspired by Benner's Novice to Expert Theory and Carper's ways of knowing, the authors personally reflected on their transition experiences during NP schooling and then collectively developed a composite reflection of the shared experience. From this exercise common themes were identified.

Conclusion: This unique reflective paper identified common themes in the experience of transitioning to the student role. Potential areas for future research-based exploration of the nurse practitioner student experience were identified. By understanding these experiences, students can be better prepared in advance and faculty can design both formal and informal support measures to better support the student experience.
\end{abstract}

\section{Introduction}

Transitioning from a Registered Nurse (RN) to a Nurse Practitioner (NP) is a significant career change, often accompanied by a complete remodeling of one's professional identity (Barnes, 2015; Faraz, 2017). Whereas many other interprofessional transitions involve sequential steps to achieve professional growth, the advanced nature of the NP role requires a distinct change in lens and clinical approach from that of an RN.

Current literature focuses on the many difficulties that novice NPs experience as they step into the advanced nursing role. Common themes addressed throughout the literature include turbulence offeelings, intrinsic and extrinsic obstacles, and role ambiguity (Faraz, 2017; Heitz et 
al., 2004; Kelly \& Mathews, 2001). Several NPs within a study conducted by Heitz et al. (2004) described the first year of practice as a 'turbulent' mixture of positive and negative feelings and smooth and challenging experiences. New NPs often perceived a gap between the education they acquired, and the expectations held in practice (Cusson \& Strange, 2008; Fitzpatrick \& Gripshover, 2016). NPs describe feelings of fear, insecurity, and disillusion, as well as interpersonal clinical challenges with other RNs (Barnes, 2015; Faraz, 2017; Heitz et al., 2004). A sense of role ambiguity surrounding the NP position within the healthcare system is noted as a theme across bodies of literature (Faraz, 2017; Heitz et al., 2004; Kelly \& Mathews, 2001; Sullivan-Bentz et al., 2010). In a study conducted by Faraz (2017), novice NPs felt a sense of isolation from other health care professionals due to their perceived positioning between a nurse and physician. NPs described a challenging lack of role understanding from all parties including patients, health care professionals, employers, and the general public (Faraz, 2017).

As current literature has clearly shown the transition of a novice NP into the workforce to be challenging, one would query if similar challenges exist during the academic training period. Unfortunately, there is a distinct dearth of research surrounding the period of academic transition from RN to NP. We would argue that the transition from expert RN to NP does not merely begin once an individual steps into formal employment; rather, this process begins the moment this individual is accepted into the NP program. RNs entering the NP program have typically reached a proficient/expert phase in clinical nursing practice and abruptly return to the novice stage upon entry to school. We feel that this transition period warrants examination.

While specific admission requirements to Canadian NP Programs vary, it is commonly required to clearly demonstrate both academic and professional excellence. Candidates provide academic transcripts, clinical and academic references, and evidence of several full-time years of nursing practice. These individuals are often viewed as leaders within their clinical practice settings (Barnes, 2015; Faraz, 2017). According to Patricia Benner's Novice to Expert model (1982), these applicants have generally reached the proficiency level of nursing expert. As these confident expert RNs enter the NP program, however, they are abruptly moved back to the novice role; one that comes with significant change in clinical approach and volumes of newly required knowledge and skill.

\section{Ways of Knowing and Reflective Practice}

Reflective practice allows nurses to examine their actions and experiences to develop their practice and expand their clinical knowledge (Mantzoukas \& Jasper, 2004). Engaging in regular self-reflective practice provides nurses with greater self-awareness and personal and professional growth (College of Nurses of Ontario, 2014).

Barbara Carper (1978) identified different ways that nurses know and practice and referred to these as patterns of knowing; two of these patterns are known as personal and aesthetic ways of knowing. Personal knowing involves the consideration and deeper knowledge of self. For example, how do our strengths and weaknesses affect our nursing practice? By having understanding of self, knowledge of another is possible, and thus influence the development of therapeutic relationships with patients (Chinn \& Kramer, 2018). Carper (1978) describes aesthetic knowing as the art of nursing, focusing on the meanings created through our 
Nurse Practitioner Open Journal

Vol 1. Issue 1 DOI 10.28984/npoj.v1i1.342

connections with others, including patients, families, and other colleagues. The aesthetics of nursing can involve the creative, expressive, and intuitive process of knowledge application (Chinn \& Kramer, 2018). The ways of knowing can provide a framework for conceptualizing and reflecting on nursing practice (Campbell et al., 2018).

As a creative exercise inspired by the theoretical underpinnings of Benner's (1982) Novice to Expert Model and Carper's patterns of knowing (1978), the authors, as former NP students, collectively reflected on the following points of time in the NP program: program orientation, beginning of first year, second year and start of clinical practicum, and second clinical practicum. From our personal reflections, we created a composite reflection about the experience of transition from an expert RN to the novice NP program student which is reflective of our collective experience. In honour of Carper's aesthetic knowing, we chose to present this collaboration creatively, as a reflective in-person narrative which captures all four voices within.

\section{Composite Reflection}

\section{Program Orientation Sessions}

Entering the NP program feels like the most logical next step in my nursing career. I feel confident in my knowledge and skills as an RN. I feel ready to challenge myself and broaden my scope of practice. Given how competitive the NP program is, being accepted gave me the extra boost of confidence in believing this is what I was meant to do. While many NPs warned me about the difficult program, I believe my hard work ethics, my RN knowledge and capabilities, and my ability to adapt will serve me well. I feel so proud and excited to be here. But I also feel intimidated...everyone seems so sure of themselves. Everyone seems so smart and confident. Today summarized what is to come over the next two years and came with constant reminders of the expectations and workload of the program. I am really not sure what I am getting myself into...but I feel some relief in knowing everyone in this room is in the same boat.

\section{Beginning of first year}

I feel very overwhelmed. I know I am an expert $R N$, and I earned that status...but that doesn't seem to mean anything here! Moving into this novice role feels so daunting and incredibly backwards. I am extremely nervous, a feeling I am not usually faced with. I do not feel confident. I feel like a deer in the headlights. I have begun to realize the magnitude of learning required to alter my mindset from providing care to prescribing that care. We are continually told by our professors "you can do this!" But can we?! What had felt so close now feels so far away. I am going to try to stick to a schedule of studying daily from 9am-6pm and keep evenings for family time. Or should I just be doing schoolwork only? Am I doing too much? Am I doing too little? In class I have been delving into the role and history of the NP and reading the literature is extremely unsettling...it seems as if NPs are always trying to defend their role and earn respect from others. It seems like physician groups really resist the role of the NP. What have I gotten myself into? 
Nurse Practitioner Open Journal

Vol 1. Issue 1 DOI 10.28984/npoj.v1i1.342

\section{Second year and the start of clinical practicum}

Just when I feel like I am caught up, I am weeks behind. The course content is extremely heavy, and I feel overwhelmed...how I am going to pull this off? When I think about all I have to learn, it feels impossible. Stepping into my first clinical placement felt like a pivotal moment...I kept telling myself, "I am an excellent nurse, I can handle this". But then immediately I realize, I have never felt so novice. I am no longer in familiar territory and it was extremely obvious to me and the patient. I didn't even know where to start when I walked into the room to see the first patient. Going clinical and feeling defeated every single shift is starting to feel like the new norm. "Get used to being wrong!" - this is not something that is easy for a former expert! I have started to call my friend, also in the program, after every clinic shift; it's becoming a common ritual known as the "postclinical debrief". We can both rant about the frustrations of the day...it's pure therapy. Despite the frustrations, I am very fortunate to have preceptors who have taken on the role of mentor... they seem to understand that much of this is completely new to me. They take the time to teach me, show me resources to use in practice, and look for opportunities for me to advance my learning. I'm also heartened by my interactions with physician preceptors; they are so supportive and welcoming! I don't understand why individual interactions are so positive about NPs but their governing bodies are so negative... will it be like this forever?

\section{Second half of year}

At this point in the program, I am starting to feel like an expert student. I have some clinical experience under my belt. I have achieved high grades and am feeling knowledgeable about the content learned so far. I am developing an increased sense of confidence within my role as a student. I am now seeing every type of patient and getting comfortable with my approach. I am feeling more at ease. I feel that I might not know enough to be an NP, but I know I can provide safe care. There is truly no better moment than being in clinical and having your preceptor agree with your diagnosis and plan of care. During this semester, the magnitude of the NP responsibility fully hits me. As an RN, care decisions are made by the physician; while I may independently advocate for changes in an individual's care as an RN, I will soon be the sole decision maker as an NP. It's on me. This is both a huge honour and incredibly scary.

\section{Themes}

As part of our discussions to create the composite reflection above, we identified several common themes throughout our experiences.

\section{Initial Confidence}

As RNs, all authors felt confidence in their role and clinical expertise. Self-identifying as experts in their nursing roles, they had previously acted as mentors to students and new graduate RNs. This confidence validated the decision to pursue graduate education, advance their scope of practice, and pursue a role as a NPs. Prior to the start of the program, the authors felt strongly 
that their nursing expertise would provide the necessary knowledge and experience needed to successfully transition from RN to NP.

\section{Role Confusion}

During the first year of the program students complete one course which outlines the role of a NP. This course provides the first introduction to the challenges encountered by practicing NPs. Through this course and beginning clinical interactions, the authors learned that the NP role varies considerably by setting and is often largely determined not by legal scope of practice, but by acceptance and support from medical and management colleagues. The excitement and anticipation towards becoming an NP in the future began to be tempered by knowledge that political climate and legislative barriers would likely pose very real obstacles in their careers.

\section{Defeat}

When entering the second year of the program, the start of clinical practice was initially seen as a welcome change after the first year of focussed study without practicum placements. The authors eagerly anticipated a return to the clinical environment, an area in which they had substantial expertise. However, they quickly realized that nursing expertise did not translate to competence at the NP level. The authors felt shocked at the limitations in their knowledge and clinical skills, not just for complex clinical cases, but for perceivably simple primary care complaints. They expressed feelings of overwhelm, frustration, and defeat because of the perceived incongruence between their current knowledge and what was required for NP competence.

\section{Humbling}

The stark reality of the enormous undertaking to become an NP was clear after their initial forays into the clinical arena in this new role. They felt humbled by the requirements of this new role. Greater appreciation was gained for the level of responsibility that accompanied even minor procedures and treatment. They were constantly learning and encountering new challenges and complexities.

\section{Coping}

Having previously excelled in undergraduate and graduate study, the authors felt prepared for the challenges of the NP program. They had also heard from previous NP graduates that the program was very difficult and relies heavily on self-direction. They quickly developed an appreciation of the unique intensity and rigour of studying to become an NP. Previous approaches for managing workload were found to be insufficient, particularly as time went on and competing demands within their personal lives came into play.

The authors began to realize that new coping methods needed to be developed. Guidance and mentorship from clinical and academic preceptors were found to be important. Learning to neutralize negative self-talk with gentle, personal reminders of the learning process were key. All authors also strongly identified the integral nature of peer support. 
Nurse Practitioner Open Journal

Vol 1. Issue 1 DOI 10.28984/npoj.v1i1.342

\section{Gaining Competency}

The authors noticed the progression of their learning toward gaining competence in the novice NP role with the start of clinical placements. Stepping out of their comfort zones as RNs and practicing in an advanced role allowed them to gain confidence and apply their advanced knowledge. Validation from their preceptors also contributed towards their development of confidence in their new role. The authors acknowledged that their clinical placements helped to shape their development from RN to NP and helped to gain competence in the primary care setting. Understanding their role as a novice NP program student provided them with motivation to persevere and challenge themselves.

\section{Adaption}

Adapting to the role transition was seen as essential. Despite initial frustration with the transition from expert to novice, with the help of mentors, preceptors and classmates through the program, the authors felt able to slowly adapt to this new life experience. Confidence in their new role as a novice NP began to grow and they began seeking out new and challenging clinical cases. During the program, the authors felt as if they moved from expert as RNs, to novice as student NPs and then proficient in the student NP role (ie. excellent at being students but still very novice as NPs).

\section{Discussion}

Using the 'Novice to Expert Model' as a reflective lens to inform this narrative has contributed to deeper insight of the non-linear nature of the transition from expert $\mathrm{RN}$ to novice NP (1982). Literature exploring the experience of newly licenced NPs entering the workforce has previously described feelings of profound lack of confidence, self-doubt, and role confusion (Barnes, 2015; Faraz, 2017); these feelings are mirrored in the author's reflection as they enter their first clinical placements. New NPs often perceived a gap between the education they acquired, and the expectations held in practice (Cusson \& Strange, 2008; Fitzpatrick \& Gripshover, 2016). Feelings of defeat in novice NPs have been described as influencing decisions about remaining in the profession (Barnes, 2015; Twine, 2018); similarly, the authors wrestled with concerns and regrets about choosing this program path.

The authors describe encountering, in student practice, the challenging role ambiguity that is also identified as a common obstacle for novice NPs (Faraz, 2017; Heitz et al., 2004; Sullivan-Bentz et al., 2010). In a study conducted by Faraz (2017), novice NPs felt a sense of isolation from other health care professionals due to their perceived positioning between a nurse and physician. NPs described a challenging lack of role understanding from all parties including patients, health care professionals, employers, and the general public (Faraz, 2017). New NPs describe adapting to the advanced role by using coping mechanisms, such as positive self-talk and seeking collegial support; coping strategies that are also described by the authors. The authors reflected on feeling sparks of confidence mixed with self-doubt and uncertainty; literature supports that these mixed and 'turbulent' feelings continue into the early NP novice years (Heitz et al., 2004). 


\section{Implications}

Interestingly, the themes identified in this reflective exercise about NP schooling were consistent with many of the described experiences during the transition into the NP workforce. We strongly feel that the transition process to becoming an NP starts at the moment one opens the program acceptance letter, instead of with graduation. Unfortunately, there is a dearth of formal research around this phenomenon. The voices of in-progress NP students are poorly represented in literature. This absence of representation can translate to limited formal understanding and direction for faculty in supporting and preparing this unique cohort of nursing students.

Due to the reflective nature of this piece, we hesitate to make formal faculty recommendations. However, with further qualitative research in the future, faculty can develop evidence-based and specific directions for mentorship and support. This small creative exercise lends potential avenues for future research-based exploration of the NP student experience within a larger group. Perhaps with better understanding of these experiences, NP faculty can design increased formal and informal support, aimed to proactively address the forthcoming program challenges. Given the overlap between experiences both at the student and novice level, a better prepared/supported NP program student may translate to a better prepared/supported novice NP and one who is less likely to re-consider the career path.

As more expert RNs strive towards advanced practice nursing, it is paramount that this transition experience is better understood. Future research is needed to better understand this unique group of nursing students.

\section{References}

Barnes, H. (2015). Exploring the factors that influence nurse practitioner role transition. Journal for Nurse Practitioners, 11(2), 178-183. DOI: 10.1016/j.nurpra.2014.11.004

Benner, P. (1982). From novice to expert. The American Journal of Nursing, 82(3), 402-407. doi:10.1097/00000446-198282030-00004

Campbell, T. D., Penz, K., Dietrich-Leurer, M., Juckes, K., \& Rodger, K. (2018). Ways of knowing as a framework for developing reflective practice among nursing students. International Journal of Nursing Education Scholarship, 15(1), 1-12. DOI: 10.1515/ijnes-2017-0043

Carper, B.A. (1978). Fundamental patterns of knowing in nursing. Advances in Nursing Science, 1(1), 13-24. DOI:10.1097/00012272-197810000-00004

Chinn, L.P. \& Kramer, M.K. (2018). Knowledge development in nursing: Theory and process (10th ed.). Elsevier

College of Nurses of Ontario. (2014). Practice reflection: Learning from practice. Retrieved from https://www.cno.org/globalassets/4- 
Nurse Practitioner Open Journal

Vol 1. Issue 1 DOI 10.28984/npoj.v1i1.342

learnaboutstandardsandguidelines/prac/learn/teleconferences/practice-reflection--learning-frompractice.pdf

Cusson, R. M., \& Strange, S. N. (2008). Neonatal nurse practitioner role transition: The process of reattaining expert status. The Journal of Perinatal \& Neonatal Nursing, 22(4), 329337. https://doi.org/10.1097/01.JPN.0000341365.60693.39

Faraz, A. (2017). Novice nurse practitioner workforce transition and turnover intention in primary care. Journal of the American Association of Nurse Practitioners, 29(1), 26-34. https://doi.org/10.1002/2327-6924.12381

Fitzpatrick, S., \& Gripshover, J. (2016). Expert nurse to novice nurse practitioner: The journey and how to improve the process. The Journal for Nurse Practitioners, 12(10), e419-e421. https://doi.org/10.1016/j.nurpra.2016.05.012

Heitz, L. J., Steiner, S. H., \& Burman, M. E. (2004). RN to FNP: A qualitative study of role transition. The Journal of Nursing Education, 43(9), 416-420. https://doi.org/10.3928/01484834-20040901-08

Kelly, N. R., \& Mathews, M. (2001). The transition to first position as nurse practitioner. Journal of Nursing Education, 40(4), 156-162. https://doi.org/10.3928/0148-4834$\underline{20010401-05}$

Mantzoukas, S., \& Jasper, M. A. (2004). Reflective practice and daily ward reality: A covert power game. Journal of Clinical Nursing, 13(8), 925-933. https://doi.org/10.1111/j.13652702.2004.01008.x

Sullivan-Bentz, M., Humbert, J., Cragg, B., Legault, F., Laflamme, C., Bailey, P. H., \& Doucette, S. (2010). Supporting primary health care nurse practitioners' transition to practice. Canadian Family Physician, 56(11), 1176-1182.

Twine, N. (2018). The first year as a nurse practitioner: An integrative literature review of the transition experience. Journal of Nursing Education and Practice, 8(5), 54-62. https://doi.org/10.5430/jnep.v8n5p54 